\title{
Ocular Adnexal Lymphoma pN2 TNM
} Finding v7

National Cancer Institute

\section{Source}

National Cancer Institute. Ocular Adnexal Lymphoma pN2 TNM Finding v7. NCI

Thesaurus. Code C88851.

Involvement of contralateral or bilateral regional lymph nodes. Note: The regional lymph nodes include preauricular (parotid), submandibular, and cervical. (from AJCC 7th Ed.) 